\title{
DA DESCONSTRUÇÃO DA INOVAÇÃO AO PAPEL ATIVO DA INOVAÇÃO SOCIAL EM AMBIENTES DE ECONOMIA SOLIDÁRIA NA CONFIGURAÇÃO DE TERRITORIALIDADES: PROPOSTA METODOLÓGICA APLICADA NO ESTUDO DE CASO RISARALDA-COLÔMBIA
}

\begin{abstract}
RESUMO
Como entender o papel da inovação social (IS) como um conjunto de práticas socioespaciais? O que implicaria tornar um conceito de natureza transformadora, numa ação coordenada completamente emergencial na formação de territórios? Neste breve texto, tenta-se levar ao leitor por uma senda metodológica, de como seria abordar a IS desde sua processualidade e o que implicaria decidir na "maneira" como a sua condição de mediação cultura-espaço se realiza, ou seja, na qualificação da ação diferenciadora (inovação), mas dentro do âmbito da economia solidária. Apresentados três estudos de caso do Departamento de Risaralda-Colômbia, buscase questionar sobre o papel ativo da IS na configuração de territorialidades, que aspectos se tornam relevantes na mediação técnico-simbólica e organizativa deste tipo de práticas, como poderia se redefinir as iniciativas de economia solidária através da auto-organização, autorrepresentação e autoprojeção que estas têm da sua própria ação coletiva?
\end{abstract}

Palavras-chave: Inovação social; Territorialidades; Economia solidária; Proposta metodológica.

\section{FROM THE DECONSTRUCTION OF INNOVATION TO THE ACTIVE ROLE OF SOCIAL INNOVATION IN ENVIRONMENTS OF SOLIDARITY ECONOMY IN THE CONFIGURATION OF TERRITORIALITIES: THE METHODOLOGICAL PROPOSAL APPLIED IN THE CASE STUDY RISARALDA - COLOMBIA}

\begin{abstract}
How to understand the role of social innovation ( $\mathrm{SI}$ ) as a set of socio-spatial practices? What would imply to become a concept of transforming nature, in a completely emergency coordinated action in the formation of territories? In this brief text, it is tried to take the reader by a methodological path, of how to approach the SI from its procedurality and what would imply to decide in the "way" how its condition of mediation
\end{abstract}


Da desconstrução da inovação ao papel ativo da inovação social em ambientes de economia solidária na configuração de territorialidades: proposta metodológica aplicada no estudo de

culture-space is realized, that is, in the qualification of differentiating action (innovation), but within the scope of the solidarity economy. Three case studies of the Department of Risaralda-Colombia were presented, the aim is to question the active role of SI in the configuration of territorialities, which aspects become relevant in the technicalsymbolic and organizational mediation of this type of practices, how could the initiatives be redefined of solidarity economy through the self-organization, self-representation and self-projection that these have of their own collective action?

Keywords: Social Innovation; Territorialities; Solidarity Economy; Methodological Proposal.

\section{INTRODUÇÃO}

A primeira questão que aqui vamos abordar é a possibilidade de dar visibilidade a três estudos de caso, três organizações de economia solidária vinculadas ao setor agrário colombiano. O primeiro ponto de partida é a necessidade de valorizar qualquer movimento de contestaçãoprojeção organizado, que dê uma resposta concreta à difícil situação do campo colombiano, um fenômeno que não é alheio ao modelo de desenvolvimento pelo qual está caminhando o país.

Dentro da escolha metodológica, pode-se dizer que um dos propósitos da pesquisa, que em realidade apresentamos aqui de maneira parcial, foi dar visibilidade ao poder de transformação da inovação social, que em ambientes solidários pode focalizar-se numa direção coerente de desenvolvimento local. Dotar de sentido a inovação social das organizações de economia solidária possibilitou dois movimentos inerentes: o primeiro, o caráter legitimador e processual da inovação abordada na adjetivação do "social" para poder "fugir" da histórica e tendenciosa condição técnico-científica e "economicista" de rentabilidade, que valoriza mais os produtos que os processos, situação que não permitia avançar no reconhecimento da inovação como prática de transformação criativa legitimada em seus ganhos coletivos; um segundo movimento, centrou-se no caráter mediador da inovação como ações coordenadas que densificariam as práticas socioespaciais, em outras palavras, uma mediação técnico-simbólica coordenada que permita olhar para os territórios de maneira processual (as ações de produção e apropriação espaciais abordadas desde o conceito de territorialidades), um aspecto fundamental na abordagem multidimensional e histórica no papel ativo da construção de territórios.

Nesta perspectiva, é suficiente questionar os processos econômicos como fatores centrais das transformações territoriais aqui abordadas? Ou pelo contrário, podemos questionar o "como" das práticas socioespaciais que, finalmente, movimentam a "energia intersubjetiva ética" que chamamos, nesta abordagem particular, de economia solidária? Pensamos que o conceito de inovação social não só se apresenta como um "impulso" criativo, mas também como um agir coletivo de legitimidade social.

Sendo assim, apresentam-se algumas noções ou conceitos básicos de inovação social e territorialidade, o que permitirá expor três estudos de caso de organizações da economia solidária do Departamento de Risaralda, Colômbia: Agrosolidaria Seccional Apía, ASCRUDCOOPROCOMD e Agrosolidaria La Celia descritos brevemente e abordados conforme a proposta metodológica que alicerça esta discussão, nessa ordem, apresenta-se um primeiro 
Da desconstrução da inovação ao papel ativo da inovação social em ambientes de economia solidária na configuração de territorialidades: proposta metodológica aplicada no estudo de

momento metodológico com o desenvolvimento de uma etapa inicial que delimita a inovação como processo discursivo, um segundo e terceiro momento corresponde à operacionalização do Sistema Local Territorial (SLOT). Deste modo, vários elementos e relações possibilitarão desvelar um primeiro esboço de territorialidades formadas através do papel ativo da inovação social em ambientes de economia solidária.

\section{QUALIFICAR A PROCESSUALIDADE DA INOVAÇÃO SOCIAL: DOTAR DE SENTIDO AS TRANSFORMAÇÕES CRIATIVAS}

Partimos da hipótese de que o amplo espectro do qual se compõe o território (social, político, econômico, cultural e ambiental), o conceito de inovação social, constituinte e transformador, mas que por sua carga paradigmática (contexto técnico-científico e suas relações com o modelo capitalista), impossibilita-se uma aplicação conveniente que coloque a economia (no tocante aos preceitos do lucro econômico) a serviço da população. Neste sentido, defendemos o argumento, de que quando a inovação social é desconstruída desde sua matriz conceitual, e ativada desde a aplicação renovada de um projeto de integração social, com processos reais de transformação, como pensamos, ocorre com a economia solidária, a própria configuração das tensões territoriais, pede ser requalificada desde o poder analítico e transformador das práticas de inovação social, o que implicaria priorizar uma abordagem territorial que dote de sentido a processualidade das iniciativas de economia solidária.

Se algo tem caraterizado a Colômbia, é a altíssima concentração da propriedade e do capital e as poucas oportunidades que apresenta o campo colombiano para a maior parte da população, principalmente a população rural, com condições ainda mais desiguais em relação às cidades. Há muitos anos (principalmente desde a Lei 454 de 1998) a economia solidária tem se apresentado como uma possibilidade de reconhecer os sujeitos outrora esquecidos pelo Estado, pois sua lógica social tem sublinhado o trabalho justo e equitativo, sabe reutilizar os excedentes das atividades econômicas em benefício para os associados, tentando equilibrar as necessidades básicas e promover os princípios de solidariedade no contexto de atuação.

O Departamento (divisão político-administrativa) de Risaralda (Figura 1), com uma forte centralidade espacial (tradicional lugar de passagem), torna-se um lugar de alto valor geográfico para o país, que, junto com outros Departamentos, tem-se constituído como o eixo cafeeiro da Colômbia. A escolha do Departamento de Risaralda além de responder a uma lógica de localização, o faz também com base no reconhecimento do ganho da governança de alguns dos municípios que conseguem construir, através dos processos de organização de economia solidária, processos de autonomia, autorrepresentação e autoprojeção. Um exemplo disso é o município de Apía, o qual demonstrou grande amadurecimento em temas de desenvolvimento local alicerçado numa consistente base solidária, hoje a maior força empresarial com poder na tomada de decisões do município.

Como pode se observar, a Figura 1 mostra cinco municípios de interesse para três estudos de caso, isto porque a abordagem feita das experiências se centra na formação de circuitos econômicos solidários, quer dizer, como redes de integração. Os três modelos apresentados são 
Da desconstrução da inovação ao papel ativo da inovação social em ambientes de economia solidária na configuração de territorialidades: proposta metodológica aplicada no estudo de caso Risaralda-Colômbia

descritos no Quadro 1, fazendo uma análise sucinta dos circuitos numa dinâmica territorial. Nesse sentido, os casos apresentados são: Agrosolidaria Seccional Apía, localizada no município que leva o mesmo nome, ASCRUD (Asociación de Comunidades Rurales Unidas) COOPROCOMD (Cooperativa de Produtores e Comerciantes de Dosquebradas), que em realidade são uma associação e uma cooperativa que atuam desde o município de Dosquebradas, mas com relações fora do Departamento e, dentro dele principalmente com Belén de Umbría e Pereira, e finalmente, Agrosolidaria La Celia que leva o mesmo nome do município.

As informações aqui apresentadas são produto do trabalho de campo feito na Colômbia no período 2015-2016 através de entrevistas semiestruturadas que teve o objetivo de identificar as práticas de inovação social das organizações de economia solidária e analisar o caráter instrumentalizador dessa inovação na construção das territorialidades.

Figura 1 - Localização da sub-região II do Departamento de Risaralda-Colômbia

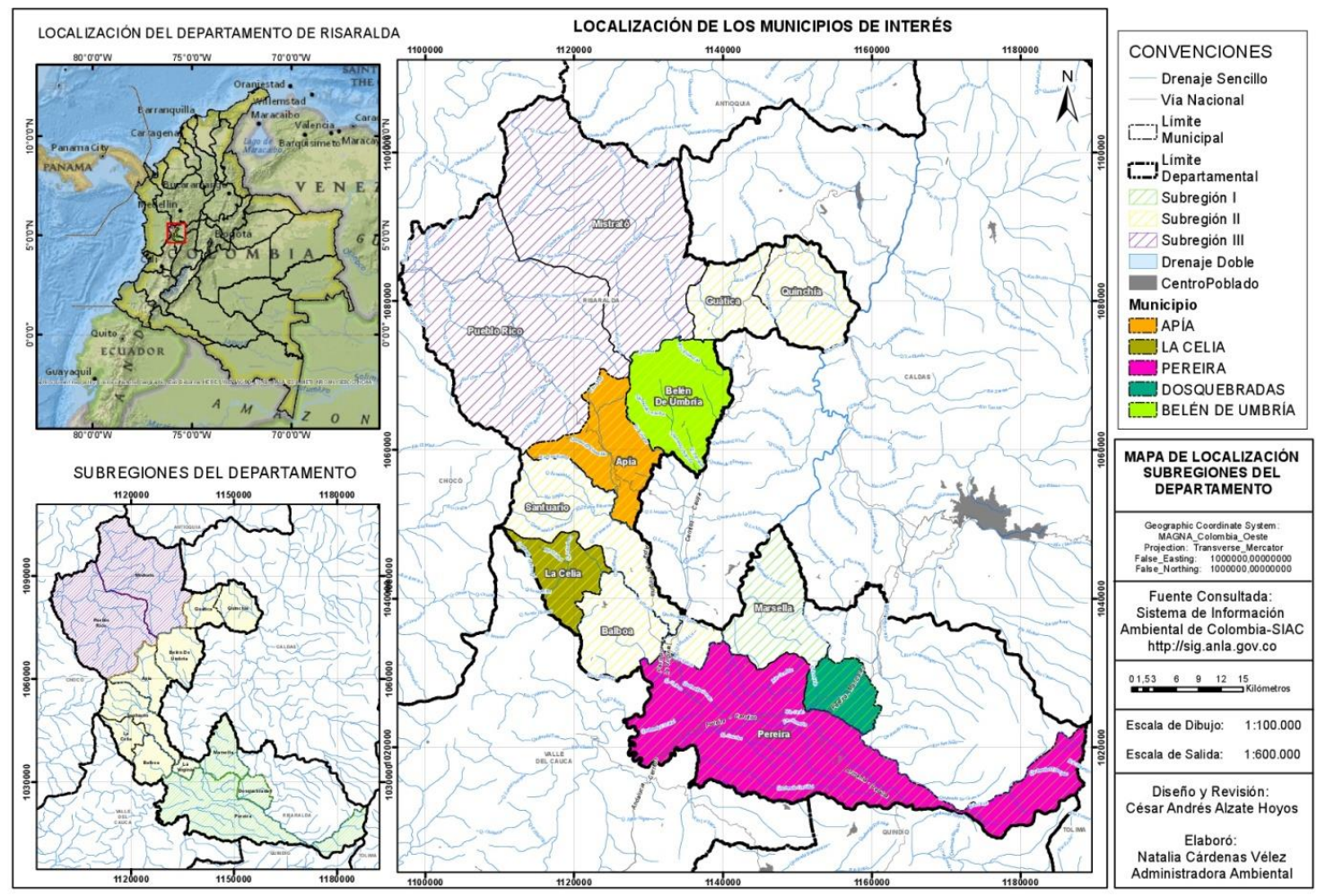

Antes de ressaltar os processos de inovação social dentro da metodologia proposta, alguns aspectos poderiam ser esclarecedores no momento de destacar as particularidades das iniciativas. No caso de Agrosolidaria Seccional Apía, cabe esclarecer que, se bem as organizações de economia solidária são definidas pela Lei 454 de 1998 as Organizações Solidárias de Desenvolvimento, como é o caso das Agrosolidarias, estão definidas num marco legal muito mais amplo. Atualmente, esta organização que conforma, junto com 128 seccionais, uma confederação que se autodefine como um processo autogerido de organização comunitária orientado a construir uma Comunidade Econômica Solidária com o emprego de recursos mistos (públicos e privados) e, por esse dizer, é de uso social (CARDENAS, 2010). Para Dennis Augusto 
Da desconstrução da inovação ao papel ativo da inovação social em ambientes de economia solidária na configuração de territorialidades: proposta metodológica aplicada no estudo de caso Risaralda-Colômbia

Rengifo Triana (que no momento da entrevista coordenava as atividades da associação risaraldense de Agrosolidaria), Agrosolidaria se comporta como um Circuito Econômico Solidário - pelo menos em nível municipal - porque está formada por grupos associativos autônomos (para cada elo do ciclo de produtividade) que são a base de toda a estrutura de Agrosolidaria.

Quadro 1 - O poder no território dos circuitos econômicos solidários

\begin{tabular}{|c|c|c|c|c|}
\hline Circuito & Informação & Tipo de poder & Âmbito/alcance & Descrição \\
\hline $\begin{array}{l}\text { Agrosolidaria } \\
\text { Seccional Apía }\end{array}$ & $\begin{array}{c}\text { Produção e } \\
\text { comercialização de } \\
\text { produtos } \\
\text { agropecuários (frutas, } \\
\text { café, mel, carne, leite } \\
\text { etc.). Município: Apía, } \\
\text { Risaralda. } \\
\text { Associados: } 132 \text {. Ano } \\
\text { de fundação: } 2008 .\end{array}$ & $\begin{array}{l}\text { Proativo, ganha } \\
\text { espaços de } \\
\text { representação e } \\
\text { de base } \\
\text { organizativa- } \\
\text { produtiva. }\end{array}$ & $\begin{array}{l}\text { Local-rural, com } \\
\text { impacto regional e } \\
\text { internacional }\end{array}$ & $\begin{array}{c}\text { Com o amadurecimento das } \\
\text { organizações, ganham-se } \\
\text { espaços de tomada de } \\
\text { decisões, gestando-se } \\
\text { sistemas de governança } \\
\text { que desencadeiam ações } \\
\text { desde a base da pirâmide } \\
\text { social; os ciclos tendem a } \\
\text { ser mais longos e contínuos, } \\
\text { porém, a atuação, assim } \\
\text { como o circuito mesmo, não } \\
\text { representa de maneira } \\
\text { organizada todos os } \\
\text { agentes. }\end{array}$ \\
\hline $\begin{array}{c}\text { ASCRUD- } \\
\text { COOPROCOMD }\end{array}$ & $\begin{array}{c}\text { Produção e } \\
\text { distribução de } \\
\text { produtos } \\
\text { agropecuários de } \\
\text { origem rural ou } \\
\text { urbano, organizados } \\
\text { através de } \\
\text { microempresas. } \\
\text { Município: } \\
\text { Dosquebradas, } \\
\text { Risaralda. } \\
\text { Associados: } 31 \\
\text { (COOPROCOMD). } \\
\text { Ano de fundação: } \\
\text { 2001. }\end{array}$ & $\begin{array}{l}\text { Proativo, } \\
\text { independente } \\
\text { dos ciclos de } \\
\text { gestão. }\end{array}$ & $\begin{array}{l}\text { Regional-urbano- } \\
\text { rural }\end{array}$ & $\begin{array}{l}\text { Com uma alta capacidade } \\
\text { de gestão, configura-se uma } \\
\text { eficiente rede de atuação } \\
\text { numa interface de } \\
\text { conurbação urbano-rural, a } \\
\text { qual implica enfrentar uma } \\
\text { estrutura político } \\
\text { administrativa mais } \\
\text { complexa, o que provoca } \\
\text { uma resistência da atuação } \\
\text { do circuito frente às } \\
\text { exigências e ciclos da } \\
\text { administração municipal, } \\
\text { isto obriga que o circuito } \\
\text { tenha que abrir novos } \\
\text { espaços de gestão. }\end{array}$ \\
\hline $\begin{array}{c}\text { Agrosolidaria La } \\
\text { Celia }\end{array}$ & $\begin{array}{c}\text { Produção e } \\
\text { comercialização local } \\
\text { (principalmente } \\
\text { banana da terra e } \\
\text { café). Município: La } \\
\text { Calia, Risaralda. } \\
\text { Associados: } 114 \text {. Ano } \\
\text { de fundação: } 2010 .\end{array}$ & $\begin{array}{c}\text { Proativo, } \\
\text { iniciante, de } \\
\text { base } \\
\text { organizativa- } \\
\text { produtiva e sem } \\
\text { uma } \\
\text { participação } \\
\text { definida nos } \\
\text { espaços de } \\
\text { democracia } \\
\text { representativa. }\end{array}$ & $\begin{array}{l}\text { Local-rural com } \\
\text { impacto regional }\end{array}$ & $\begin{array}{l}\text { Ainda muito novo, este } \\
\text { circuito pertence a uma } \\
\text { iniciativa totalmente de base } \\
\text { social respondendo de } \\
\text { maneira organizada às } \\
\text { demandas dos associados. } \\
\text { Levando em consideração o } \\
\text { marcado poder político } \\
\text { tradicional, a atuação } \\
\text { política se faz mais na } \\
\text { abertura de novos espaços } \\
\text { (participação social) que } \\
\text { convoquem os interesses } \\
\text { dos associados. }\end{array}$ \\
\hline
\end{tabular}

Fonte - Elaboração própria (2015), a partir de entrevistas realizadas 
Da desconstrução da inovação ao papel ativo da inovação social em ambientes de economia solidária na configuração de territorialidades: proposta metodológica aplicada no estudo de

Apía é um território que se caracteriza por ser densamente associativo (32 organizações). O cofundador e atual presidente de Agrosolidaria Seccional Apía e ex-prefeito do município Francisco Javier Alzate Vallejo, acredita ter conseguido um avanço enorme no transcurso destes anos a partir da integração de diferentes organizações, um esquema de desenvolvimento local através de um circuito econômico solidário, apoiado desde sua administração na prefeitura no período 2004-2007. Não obstante, e como será visível posteriormente, embora o papel de Agrosolidaria tenha sido fundamental na integração e fortalecimento de muitas organizações, hoje com o amadurecimento das mesmas, não veem em Agrosolidaria uma função muito esclarecida. Isto se deve, em parte, a que teve uma fundação bastante rápida, o que deixa entrever algumas falhas organizativas que comprometem a função integradora da organização.

Contudo, sobressaem como ganhos muito importantes, a união dos tenderos (donos de lojas de bairro que vendem no varejo) que tem priorizado a compra de alimentos locais e outros adquiridos de maneira conjunta para diminuir custos de logística e intermediação, a Asociación de Cultivadores de Apía (ASOAPIA) especializada na produção e comercialização de cafés especiais que exercendo um papel político relevante no município e na região. Outro exemplo é a Cooperativa Multiactiva de Ganaderos y Comerciantes de Risaralda (COOPGACOR) que tem desenvolvido internamente grandes avanços nos direitos dos trabalhadores com envolvimento nos processos da organização, além de abastecer $100 \%$ do consumo de carne no mercado local e, hoje vista como uma empresa exemplar, como um patrimônio do município, parte dessa identidade é construída através de um coletivo organizado, 32 organizações que atuam em diferentes áreas (Andrés Hoyos, associado e representante legal da cooperativa, Apía, 2015).

Por outro lado, Agrosolidaria La Celia é bastante diferente com respeito a Apía, este é um município com um sistema agroalimentar bastante incipiente, com uma dependência enorme no consumo de alimentos de primeira necessidade. Sendo assim, os principais e primeiros produtos de produção e comercialização em que a organização tem se focado são o café e a banana-daterra. Segundo William de Jesus Álvarez Chica, representante legal de Agrosolidaria La Celia, 90\% dos alimentos não são produzidos no município. "É um problema cultural e político que não nos deixa sair do paradigma de dependência e insegurança alimentar, em que os cultivos para a alimentação não são vistos como itens rentáveis", salienta William de Jesus Álvarez. Como ratifica o entrevistado, desde que se constitui em 2010 Agrosolidaria, esta foi pensada para a ação e autonomia do fortalecimento do sistema alimentar do município, não no assistencialismo.

Desde o momento da fundação até hoje, tem-se conseguido ganhos importantes, principalmente culturais e políticos em torno à integração de forças, a procura do comércio justo e na luta política, ainda marginal, mas com projeções na governança territorial. Com assistência técnica, um comitê de trabalho de melhoramento dos sítios e certificação, um Fundo Rotativo e um ponto fixo de venda, tem se avançado no bem-estar e coesão social como princípios da solidariedade através do fortalecimento específico de produtos com a banana-da-terra, que atualmente e, a partir de um processo de coletivização, é reguladora do preço do mercado e com aumentos notáveis na rentabilidade (em mais de 70-80\%) e volume (480 toneladas/mês) e, o café, com melhorias na qualidade, maior garantias na produção e na venda deste produto. Além de participar no mercado institucional de alimentos em restaurantes escolares, para o qual se adquiriram hortas e insumos 
Da desconstrução da inovação ao papel ativo da inovação social em ambientes de economia solidária na configuração de territorialidades: proposta metodológica aplicada no estudo de

para a sua produção. Atualmente William de Jesus Álvarez, assim como outros entrevistados, visualizam a futuro uma organização exercendo uma proposta de modelo produtivo-comercial e político-administrativa para o município com uma política de desenvolvimento territorial.

A Cooperativa de Productores y Comerciantes de Dosquebradas (COOPROCOMD) e a Asociación de Comunidades Rurales Unidas (ASCRUD) como duas organizações mutuamente colaborativas e complementares, localizam-se na cidade de Dosquebradas que forma parte da conurbação Pereira-Dosquebradas que junto com La Virginia conformam a Área Metropolitana de Centro Occidente a qual concentra $73,59 \%$ da população do Departamento de Risaralda. Segundo Fernando Betancourt Méndez, membro do conselho de administração de Cooplarosa (Cooperativa La Rosa), a organização funda os mercados camponeses de Dosquebradas em 2001 e vendo a necessidade de melhorar a comercialização dos camponeses, no ano de 2007 apresentam uma proposta para a Ecopetrol para formar as Tiendas Campesinas (pontos fixos de comercialização) e a Central de Acopio (central de armazenagem e distribuição de produtos). Porém, das 100 lojas instaladas, após 3-4 meses $60 \%$ das lojas estavam fechadas, e com isto se perde o apoio da prefeitura por afinidade política.

Como destaca Fernando Betancourt, alguns ganhos notáveis são o Premio Escuela Empresa no ano 2012, também o programa radial "El Campo Mi Empresa" (2012, 2013, 2015), no qual se discutiam temas referentes ao campo e, em 2014 fazem parte de "Risaralda Vive Digital", para a adequação de uma Aulateca (sala interativa) com o intuito de realizar processos de alfabetização em sistemas informáticos. Outro aspecto a ressaltar, é a adequação de uma Agrovila destinada à produção de alimentos, culturas experimentais, venda de produtos, sala de conferências, armazenagem de maquinaria, recepção de hóspedes e futuramente com intuito de formar uma escola de formação em temas agropecuários. Além das iniciativas de industrialização de polpas de fruta e carnes processadas.

Para saber como se conforma o circuito econômico solidário, devemos entender que as duas organizações, e uma terceira, Cooplarosa, trabalham de maneira conjunta, apresentando-se esta última, como foi expresso por Fernando Betancourt, como "músculo financeiro" e por suposto como grande respaldo institucional, já que é uma entidade com mais de 55 anos, que tem uma linha de créditos brandos oferecidos pela cooperativa Multiactiva, dinheiro que bem pode retornar como capital institucional ou como aporte e crédito (Fundo Rotativo). Como parte do modelo de comercialização, o Fundo Rotativo e os aportes mensais também podem ser feitos em espécie com os produtos do associado. Esta iniciativa parte de duas debilidades, conforme assinala 0 entrevistado, a transformação para dar valor agregado à produção agropecuária e à comercialização, primeiro em nível interno e aprendendo com a experiência de ASCRUD, vendendo na Central de Acopio e distribuindo nas lojas próprias e outras em convênio. Os módulos empresariais com maior destaque e que revelam justamente processos de integração, são: o café em Belén de Umbría (que unificou 14 marcas de café), os Chorizos (enchidos de porco e boi) com uma única planta de transformação, ou o cacau em Marsella com 25 produtores em um único sistema de comercialização.

Dando continuidade ao argumento basilar do texto, "o papel ativo da inovação social na 
Da desconstrução da inovação ao papel ativo da inovação social em ambientes de economia solidária na configuração de territorialidades: proposta metodológica aplicada no estudo de

construção de territorialidades", questionamo-nos, como deveria ser abordada a inovação social, que critérios num campo relacional permitiriam identificar e analisar as práticas de inovação social numa dinâmica processual?

Primeiramente, para tentar abordar este questionamento, o que seria a inovação social? A inovação não é um conceito meramente econômico, inclusive seu reconhecimento social interpõe uma série de valores que podem mudar esse paradigma, social, político e científico. Neste sentido, apesar dele ter carregado historicamente com um contexto de aplicação reduzida, a abordagem da inovação social redefine a própria matriz da inovação, pois expõe a estreita visão de: inovação igual desenvolvimento técnico-científico e rentabilidade monetária, o mercado já não é um único indicador de êxito, vender só torna a inovação vendível, e conduzi-la por essa esteira simplificaria o dinamismo das transformações sociais e sua capacidade de reinventar-se, de reinventar o mundo.

Desde há mais de três décadas que a inovação é retomada de maneira tardia da teoria de Joseph Schumpeter dos anos de 1920, e é incorporada como elemento estruturante das políticas de reconversão industrial no contexto problemático da crise energética na metade dos anos setenta e da reconversão industrial associada com ela (ALZATE, 2013). De acordo com Gibbons (1997), estas políticas se estabeleceram num território difuso, entre as políticas industriais e as políticas de ciência e tecnologia, sem deixar de falar das políticas de educação superior.

Transcendendo esse reducionismo tecno-econômico, a inovação social traz um aporte valiosíssimo na perspectiva de focalizar a sociedade no centro das transformações, desvelando as intenções das ações coletivas, sua conectividade "sócio-espacial", e a processualidade histórica, as redes que direta e indiretamente constroem a inovação e se territorializam por meio das ações e representações dos sujeitos.

Um processo de inovação social implica a interação de um conjunto de atores, ou seja, uma ação coletiva (de natureza relacional), num contexto determinado (mas em ambientes interligados e interativos na produção e coprodução do conhecimento), em que se geram novas ideias, conceitos, enfoques, práticas ou aplicações (uso do conhecimento na práxis) com potencial de transformação criativa numa estrutura de legitimação social. Ademais, com destacada ênfase na sua natureza processual, busca-se ir além da materialização do produto, isto é, como processo de inovação, que não surja da "[...] confluência circunstancial de uma série de elementos, mas de uma sistemática que faz com que a inovação possa ser considerada um conjunto de atividades articuladas que se repetem uma e outra vez (quer dizer, um processo)" (SACANELL, 2009, p. 82, grifo nosso, tradução nossa).

Neste sentido, a inovação precisa ser entendida como um processo interativo de construção horizontal/transversal, considerando-se o relacionamento coletivo e participativo, a reinvenção organizativa, o reconhecimento de diversas fontes de conhecimento (ALZATE, 2013), a acumulação do aprendizado e o sistema reticular inter e transterritorial na consolidação da inovação. Em outras palavras, através de um sistema reticular, social e territorialmente organizado. Segundo afirma Morales (2009, p. 47, tradução nossa), diversos autores - como Rothwell (1991) - "[...] preconizam que os processos de inovação de última geração são aqueles fundados na integração de sistemas e redes de cooperação, e, portanto, em que os elementos 
Da desconstrução da inovação ao papel ativo da inovação social em ambientes de economia solidária na configuração de territorialidades: proposta metodológica aplicada no estudo de

relacionais [...] têm um papel-chave para seu desenvolvimento". Além disso, a inovação deve implicar num modelo de governança, entendido como organização da ação coletiva por meio da institucionalização formal e informal (ANSHELL; GASH, 2008). O que implicaria autonomia, democracia, legitimação social e autogoverno no desenvolvimento territorial.

Tendo em vista que a inovação social provoca um forte impacto, transmissível e replicável, sua capacidade deve ser sistemática, de materialização e de difusão, inserindo-se desde o campo mais interativo e relacional da imaterialidade do território, como é a linguagem, com seu poder de transformação implícito no discurso (diversidade semântica e desconstrução e construção de novos conceitos), até a materialidade mais evidente no desenvolvimento de um território, como os circuitos de troca comercial, sistemas de mobilidade, e demais fluxos e fixos que mudam as mesmas relações espaço-temporais aí estabelecidas.

Recapitulando, para aproveitar o poder processual das inovações sociais estudadas, será utilizada a primeira etapa da metodologia, desenvolvida na pesquisa principal de Alzate (2016), que se intitula "Interfaces Territoriais para Estudos de Práticas de Inovação Social em Ambientes Solidários". Assim, a importância de empregar esta etapa é que permite descrever a inovação como processo, para este fim, utiliza-se o enunciado como unidade linguística principal que busca estabelecer os limites elementares do discurso.

Neste sentido, por que alicerçar uma metodologia sobre um enunciado? Para dar resposta a este questionamento vamos tomar algumas ideias de Azevedo (2006), mesmo que nossa abordagem teórica se afaste de seus fundamentos. Por um lado, e como apresenta a autora, antes de analisar o enunciado, devemos entender que a Semântica Argumentativa de Oswald Ducrot (1988, 1989, 1999 e 2001), fundamenta-se na corrente estruturalista de Ferdinand Saussure e a Teoria da Enunciação de Benveniste (1989), dito estruturalismo linguístico baseado sobre os princípios de relação e objetividade em que o "sistema" como estrutura social, como língua e organização político-econômica prima sobre os valores individuais atribuídos ao falante, como atitudes, comportamentos e escolhas. Cabe esclarecer aqui que esse sistema "formal" que procura independência dos fenômenos sociais, ou seja, o carácter auto-referencial da língua, explicada nos princípios da sua própria racionalidade (AZEVEDO, 2006), não fazem parte de nossa fundamentação teórico-metodológica.

Porém, retomamos a ideia central do enunciado como uma unidade linguística de nível elementar e, a enunciação, de acordo com Benveniste (1989), pressupõe uma realização, em que o enunciado, numa sequência de elementos interligados que em "intimidade" com o locutor, produziria o discurso, desse modo, o enunciado é uma realidade empírica, um segmento do discurso (unidade complexa) que comporta o sentido da linguagem (AZEVEDO, 2006). Conforme o apresentado, este elemento se torna um instrumento muito valioso para delimitar e dotar de sentido processual a inovação social, que encontra no ato da(s) "fala(s)", uma representação da complexa realidade, o que implica colocar num campo relacional as interpretações, intencionalidades e experiências dos entrevistados.

Uma das primeiras inquietações no momento de desenvolver esta primeira etapa, era se teríamos alguma referência de tipo metodológico que permitisse suportar melhor nossa proposta. E, de fato, a Metodologia de Sistemas Brandos (Soft Systems Methodology) (MSB), desenvolvida 
Da desconstrução da inovação ao papel ativo da inovação social em ambientes de economia solidária na configuração de territorialidades: proposta metodológica aplicada no estudo de caso Risaralda-Colômbia

nos anos de 1970 por Peter Checkland e encorpada por estudos da Lancaster University. Está metodologia, que têm transitado em seus inicios na resolução de problemas da engenharia e, aplicada desde um período relativamente recente, na área da administração, trás alguns elementos interessantes, sobretudo, no que respeita a um uso prático do pensamento sistémico.

De maneira muito sucinta, o que nos interessa é a aplicação que a metodologia tem com "sistemas da atividade humana", como explica Checkland (1990), estes sistemas têm uma propriedade emergente que remete a "ações com propósito" baseadas na experiência e na intencionalidade. "Esta essência do "propósito" sempre se expressa como um processo de transformação [...]" (CHECKALND, 1990, p. 36). Em rigor, nosso sistema "primário", delimitado pelo enunciado, não possui de maneira visível os elementos de entrada, transformação e saída, assim como de comunicação e controle que comporia, à risca, um sistema. Contudo, queremos ressaltar a capacidade relacional que acarreta abordar a inovação social de maneira processual e ancorada numa realidade atribuível a um conjunto de percepções que constituem uma "ação manifesta" de transformação, nessa ordem de ideias, o intuito está em determinar a Ação principal (resultado de um processo empírico direcionado pelo pesquisador) e os Atributos que se possibilitam ou obstaculizam numa realidade espaço-temporal (Tecido Circunstancial) própria de cada contexto (Figura 2).

Figura 2 - Representação gráfica da inovação social como enunciado

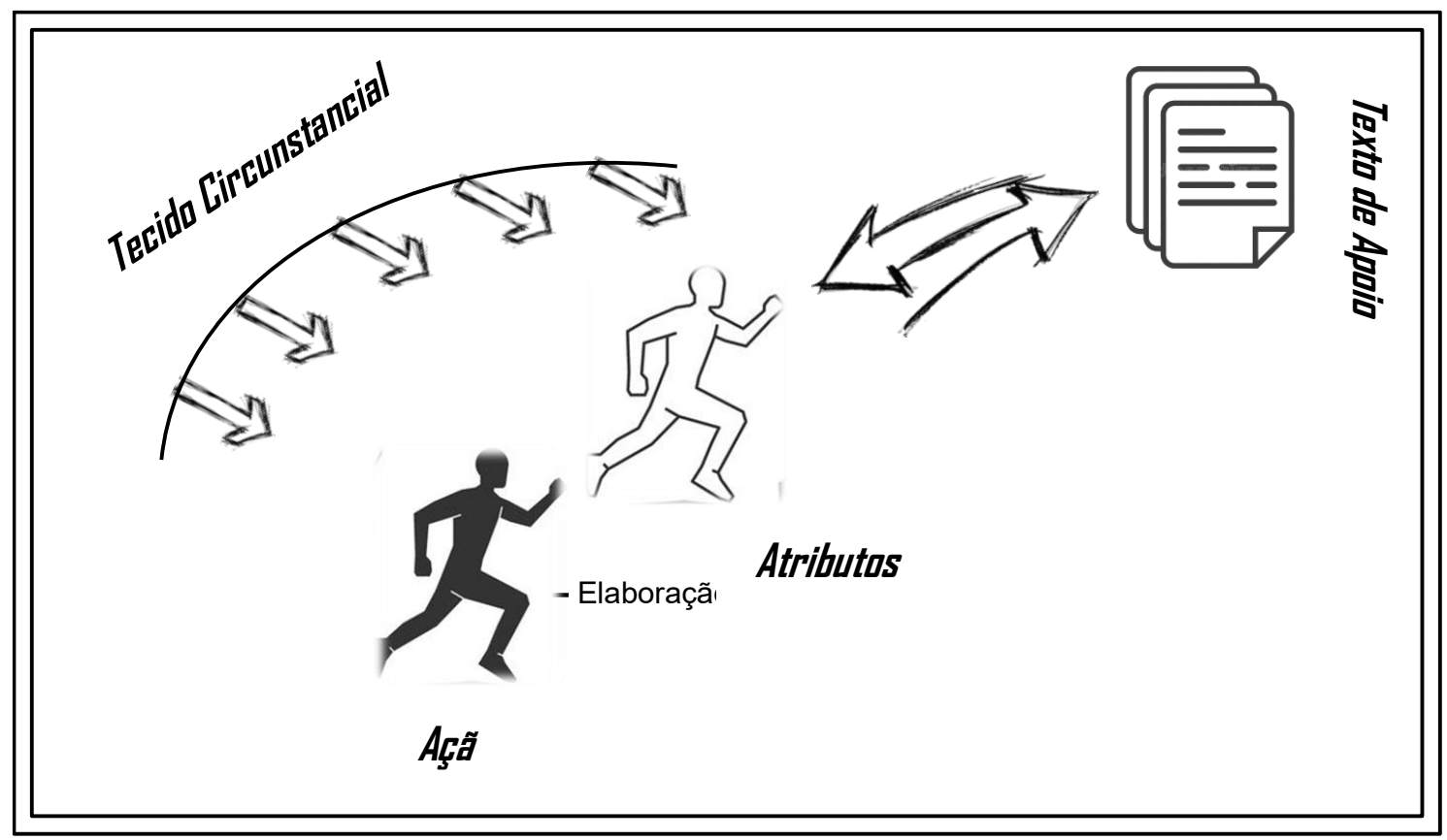

A continuação, serão delimitadas as inovação sociais a partir de dois passos apresentados no Quadro 2: o primeiro é a atribuição da Ação no "Verbo" principal da inovação, a qual descreve seu processo; o(s) Atributo(s) da inovação, que apresenta(m) as principais qualidades do processo, este será representado pelo(s) "Adjetivo(s)", denominando-os de positivos ou 
Da desconstrução da inovação ao papel ativo da inovação social em ambientes de economia solidária na configuração de territorialidades: proposta metodológica aplicada no estudo de

negativos; e finalmente o(s) "Advérbio(s)", com a capacidade de modificar a Ação (Verbo) e os Atributos (Adjetivos) dentro do que chamamos de Tecido Circunstancial, com a capacidade de quantificar, ordenar (afirmar, negar, questionar ou imprimir dúvida) e atribuir-lhe propriedades espaço-temporais à inovação. E, um segundo passo, é A Inovação num Enunciado, no qual se constrói uma unidade linguística que permite enunciar e controlar a representação verbal da inovação, ou seja, sua ação propositiva, para torná-la mais esclarecida, precisa e moldável. Este enunciado conta ademais com um Texto de Apoio, com o intuito de complementar o enunciado com mais elementos verbais, o qual deve ser o mais conciso possível. Trabalhar a inovação social dessa maneira permite delimitar uma ação principal, que no caso da organização Agrosolidaria Seccional Apía (ASA) é "fortalecer as organizações", em outros casos, "gerir" ou "transformar". Por exemplo, cada ação de cada experiência é produto de uma necessidade, um contexto, um objetivo e uma visão particular de mundo, um exemplo disso, é que "transformar o perfil produtivo" do município como principal intuito de Agrosolidaria La Celia (ALC), parece mais importante num contexto de alta dependência agroalimentar, mas com uma potencialidade do uso do solo bastante considerável. Outro aspecto a levar em conta são os atributos, aqueles que expressamos com adjetivos e representam e qualificam o conteúdo da ação (Figura 2), a estratégia - como uma qualificação atribuída - utilizada para poder atingir dito fim. De novo, isto diz muito da organização e da sua funcionalidade como rede (circuito) num contexto particular. Para exemplificar este argumento, salienta-se o "autoconsumo organizado" da ASCRUDCOOPROCOMD (AC) que corresponde com certa autonomia e principalmente com uma adequada estrutura administrativa e financeira, o que não acontece com ALC que depende, de fato, de legitimar primeiro os processos de governança.

Aliás, o chamado Tecido Circunstancial coloca em contexto os alcances das estratégias, permite valorizar o papel que ocasionalmente poderia ter a inovação no futuro, quer dizer, a criação acelerada de ASA não permitiu planejar melhor sua atuação e diminuir alguns obstáculos, ou no caso de ALC, a pequena dimensão do território mostra uma aparente acessibilidade no comando político, porém, os poderes intensos e altamente influentes que hoje atuam fazem parte de uma identidade difícil de ser alterada no curto prazo. Eis a importância de entender as ações dos sujeitos num plano espaço-temporal, que estimula ou bloqueia a aplicabilidade e impacto da inovação. 
Da desconstrução da inovação ao papel ativo da inovação social em ambientes de economia solidária na configuração de territorialidades: proposta metodológica aplicada no estudo de caso Risaralda-Colômbia

Quadro 2 - Descrição das Inovações sociais numa lógica linguística

\begin{tabular}{|c|c|c|c|c|c|}
\hline $\begin{array}{c}\text { Organização da } \\
\text { IS }\end{array}$ & Verbo Principal & $\begin{array}{l}\text { Adjetivo(s) } \\
\text { Principal(is) }\end{array}$ & $\begin{array}{l}\text { Advérbio(s) } \\
\text { Principal(is) }\end{array}$ & $\begin{array}{l}\text { A inovação } \\
\text { num } \\
\text { Enunciado }\end{array}$ & Texto de Apoio \\
\hline $\begin{array}{l}\text { Agrosolidaria } \\
\text { Seccional Apía }\end{array}$ & $\begin{array}{l}\text { Fortalecer as } \\
\text { organizações. }\end{array}$ & Visão integral. & $\begin{array}{c}\text { (+) Aqui, além, } \\
\text { ademais }(-) \\
\text { depressa, ontem. }\end{array}$ & $\begin{array}{l}\text { Fortalecer as } \\
\text { organizações } \\
\text { através da } \\
\text { visão integral } \\
\text { de um circuito } \\
\text { econômico } \\
\text { solidário. }\end{array}$ & $\begin{array}{l}\text { Levando em conta seu } \\
\text { papel solidário, para e } \\
\text { sobre as empresas, } \\
\text { esta inovação vai } \\
\text { além, trabalhando por } \\
\text { um desenvolvimento } \\
\text { local; porém, sua } \\
\text { constituição foi muito } \\
\text { rápida e seu papel } \\
\text { atualmente é a } \\
\text { lembrança do que foi } \\
\text { no passado (ontem). }\end{array}$ \\
\hline $\begin{array}{c}\text { ASCRUD- } \\
\text { COOPROCOMD }\end{array}$ & $\begin{array}{l}\text { Gerir um modelo } \\
\text { de } \\
\text { comercialização. }\end{array}$ & $\begin{array}{c}\text { Autoconsumo } \\
\text { organizado e } \\
\text { eficaz. }\end{array}$ & $\begin{array}{c}(+) \text { Dentro, } \\
\text { constantemente, } \\
\text { satisfatoriamente } \\
(-) \\
\text { dependentemente. }\end{array}$ & $\begin{array}{c}\text { Gerenciar um } \\
\text { modelo de } \\
\text { comercialização } \\
\text { reticular através } \\
\text { do } \\
\text { autoconsumo } \\
\text { organizado e } \\
\text { eficaz. }\end{array}$ & $\begin{array}{l}\text { É uma inovação que } \\
\text { aproveita os recursos } \\
\text { que ficam dentro da } \\
\text { organização, atuando } \\
\text { satisfatoriamente sobre } \\
\text { as principais } \\
\text { necessidades dos } \\
\text { associados; não } \\
\text { obstante, pode ser } \\
\text { uma inovação } \\
\text { dependentemente } \\
\text { configurada e } \\
\text { projetada frente às } \\
\text { ações e interesses de } \\
\text { outros agentes. }\end{array}$ \\
\hline $\begin{array}{l}\text { Agrosolidaria La } \\
\text { Celia }\end{array}$ & $\begin{array}{l}\text { Transformar o } \\
\text { perfil produtivo. }\end{array}$ & $\begin{array}{l}\text { Bom governo, } \\
\text { autônomo e } \\
\text { socialmente } \\
\text { legitimado, } \\
\text { economia } \\
\text { solidária } \\
\text { autossustentável. }\end{array}$ & $\begin{array}{l}(+) \text { Hoje, } \\
\text { doravante }(-) \\
\text { ainda, poderes } \\
\text { intensamente } \\
\text { influentes. }\end{array}$ & $\begin{array}{l}\text { Transformar o } \\
\text { perfil produtivo } \\
\text { do município } \\
\text { através de um } \\
\text { autogoverno } \\
\text { alicerçado } \\
\text { sobre o bem- } \\
\text { estar. }\end{array}$ & $\begin{array}{l}\text { Em outras palavras, } \\
\text { uma inovação com a } \\
\text { capacidade de mudar } \\
\text { (hoje e doravante) as } \\
\text { relações sociais em } \\
\text { uma economia mais } \\
\text { solidária e } \\
\text { autossustentável e um } \\
\text { bom governo, } \\
\text { autônomo e } \\
\text { socialmente } \\
\text { legitimado. A inovação } \\
\text { tem que fazer frente à } \\
\text { estreita e curta visão } \\
\text { das duas forças } \\
\text { intensamente } \\
\text { poderosas (Prefeitura } \\
\text { e Igreja), que ainda } \\
\text { permanecem nos } \\
\text { imaginários da } \\
\text { população e, que em } \\
\text { consequência, } \\
\text { terminam configurando } \\
\text { o território sob estas } \\
\text { condições. }\end{array}$ \\
\hline
\end{tabular}

Fonte - Elaboração própria (2015), a partir de entrevistas realizadas. 
Da desconstrução da inovação ao papel ativo da inovação social em ambientes de economia solidária na configuração de territorialidades: proposta metodológica aplicada no estudo de caso Risaralda-Colômbia

\section{O PAPEL ATIVO DA INOVAÇÃO SOCIAL NA CONFIGURAÇÃO DE TERRITORIALIDADES}

Uma vez delimitadas as inovações sociais, questionamo-nos como poderia se qualificar a inovação como uma prática socioespacial legitima e essencial no processo de mediação culturaespaço, no próprio processo de construção e apropriação territorial? Neste ponto é que as territorialidades se apresentam como relações sociais, criadas e projetadas, energia e informação, isto quer dizer que, o território como resultado das territorialidades pode ser definido como "[...] um conjunto de relações que se originam num sistema tridimensional sociedadeespaço-tempo em vias de atingir a maior autonomia possível, compatível com os recursos do sistema" (RAFFESTIN, 1993, p. 160).

O caráter relacional da concepção de Raffestin (1993) se faz evidente nas relações sociais que os sujeitos estabelecem com diferentes elementos (relações de poder, dominação, redes de circulação e comunicação, entre outros) do seu lugar, em que a apreensão dessas relações no seu contexto histórico e espaço-temporal vão determinar consequentemente as territorialidades.

Como salienta Souza (2013, p. 97) "o território corresponde a uma faceta do espaço social (ou, em outras palavras, a uma das formas de qualificá-lo) [...] Se o poder é uma das dimensões das relações sociais, o território é a expressão espacial disso". Para Arendt (1985), o poder envolve um grupo de pessoas, o que implica um exercício de consenso, assim como a liderança de um agente legitimado que o exerce (BRITO, 2002), contrário à violência que tem um caráter instrumental que se opõe ao poder (ARENDT, 1985). De acordo como Picinatto et al. (2009), o território ganha importância quando é abordado a partir das relações de poder e, sobretudo, quando o território é visto como produto "produzido" e "consumido" pela prática sócio-espacial. Daí a importância de entender o poder não exclusivamente como manipulação e relação assimétrica, e sim, segundo o pensamento de Castoriadis, como a capacidade que tem o poder de ser autônomo (radicalmente democrático) (SOUZA, 2013), pois, "onde há relações de poder, em cada território substantivado, há condições para a resistência, para a insurreição e movimentação [...] resistências precisam, para serem efetivadas, significar contraponto, diferencialidade, oposição [...] (SAQUET, 2011, p. 98).

Neste processo, segundo Gagliotto et al. (2009, p. 43), "a territorialidade não é só o modelo do espaço, mas também as características dos indivíduos e dos grupos que constituem um território". Matte e Mosquera (2009, p. 20) compartilham as ideias de Deleuze e Guattari (1976), os quais compreendem o território ligado à subjetividade individual e coletiva, nas dimensões culturais, econômicas e existenciais, "ocorre uma preocupação com o vivido, com as mudanças, ou seja, com o movimento que envolve cada situação espaço-tempo".

Podemos entender as territorialidades em Saquet (2009) como relações sociais em movimento, isto é, as territorialidades são processuais e multitemporais, ou seja, continuidades (permanências) e descontinuidades (rupturas, mudanças); históricas (diacronia) e coexistentes (sincronia) em uma unidade espaço-temporal. Ademais, são multidimensionais, e em decorrência, relações sociais simétricas ou dessimétricas produzidas historicamente; são dialéticas, portanto, materiais e imateriais, contraditórias e complementares; são transescalares, efetuam-se na vida cotidiana, estão intimamente ligadas a cada lugar, elas Ihe dão identidade; implicam fluxo, especialmente quando se revelam na construção de nós e redes de circulação e comunicação. As territorialidades revelam-se nas desigualdades socioeconômicas e político-culturais, ou, também, podem traduzir-se "numa territorialidade ativa, que pode ser concretizada através da organização política e do planejamento participativo" (SAQUET, 2009, p. 88).

Com ânimo de compreender as territorialidades identificadas nos três estudos de caso, expõemse uma síntese dos principais elementos e as relações estabelecidas que foram identificadas em três momentos e consignadas na Figura 3. Um primeiro momento corresponde ao desenvolvimento completo da metodológica "Interfaces Territoriais para Estudos de Práticas de Inovação Social em Ambientes Solidários" da qual apresentamos a primeira etapa no Quadro 2 (ver o resto das etapas no Quadro 3$)^{1}$. E, um segundo e terceiro momento desenvolvido na

\footnotetext{
${ }^{1}$ A metodologia proposta se encontra de maneira completa na dissertação denominada "Circuito Econômico Solidário: Transformações Territoriais através de Práticas de Inovação Social na Sub-Região II do Departamento de Risaralda-
} 
Da desconstrução da inovação ao papel ativo da inovação social em ambientes de economia solidária na configuração de territorialidades: proposta metodológica aplicada no estudo de caso Risaralda-Colômbia

operacionalização (com entrevistas e questionários) do modelo SLoT (Sistema Local Territorial) utilizando elemento de Dematteis e Governa (2005) e Santangelo (2005), e assinaladas em duas etapas: 1) as interdependências do capital territorial na escala relacional e 2) a auto-organização, autorrepresentação e autoprojeção da ação coletiva na construção de territorialidades. Deste modo, a Figura 3 exibe vários níveis de territorialização trabalhados por Turco (2010).

Quadro 3 - Etapas da Metodologia de Interfaces Territoriais para Estudos de Práticas de Inovação Social em Ambientes Solidários

\begin{tabular}{|c|c|c|}
\hline Etapas & Elementos & Descrição \\
\hline \multirow{5}{*}{$\begin{array}{c}\text { Etapa 1: } \\
\text { Definição das } \\
\text { inovações } \\
\text { sociais. }\end{array}$} & Verbo principal. & Ação, a qual descreve seu processo. \\
\hline & Adjetivo(s) principal(is). & $\begin{array}{l}\text { Atributo(s) que apresenta }(\mathrm{m}) \text { as principais qualidades do } \\
\text { processo. }\end{array}$ \\
\hline & Advérbio(s) principal(is). & $\begin{array}{l}\text { Com a capacidade de atribuir-Ihe propriedades espaço- } \\
\text { temporais à inovação. }\end{array}$ \\
\hline & A inovação num enunciado. & $\begin{array}{l}\text { Unidade linguística que permite enunciar e controlar a } \\
\text { representação verbal. }\end{array}$ \\
\hline & Texto de apoio. & Complementar o enunciado com mais elementos verbais. \\
\hline \multirow{4}{*}{$\begin{array}{c}\text { Etapa 2: } \\
\text { Descrever as } 4 \\
\text { Matrizes- } \\
\text { Elemento: } \\
\text { objetivos e } \\
\text { indicadores. }\end{array}$} & M1. Movimento da Interface. & $\begin{array}{l}\text { Define o campo reticular da interface através do } \\
\text { movimento. Estes se representam em três interfaces: } \\
\text { socioespacial, cultural e ecossistêmica. }\end{array}$ \\
\hline & M2. Conteúdo da Interface. & $\begin{array}{l}\text { Substantiva o conteúdo atribuindo-lhe uma designação } \\
\text { nominal à Ação, ao Atributo e ao Tecido Circunstancial. }\end{array}$ \\
\hline & M3. Energia Intersubjetiva. & $\begin{array}{l}\text { Define as necessidades, desejos e projeções coletivas } \\
\text { frente à Matriz de Análise Conteúdo-Forma-Movimento } \\
\text { (COFOM). }\end{array}$ \\
\hline & M4. Forma da Interface. & $\begin{array}{l}\text { Define a forma da interface a partir do visível, sendo uma } \\
\text { interface Físico-Construída, Físico-Natural ou Social. }\end{array}$ \\
\hline $\begin{array}{l}\text { Etapa 3: } \\
\text { Indicadores e } \\
\text { intensidade. }\end{array}$ & $\begin{array}{l}\text { Indicadores e intensidade do } \\
\text { indicador. }\end{array}$ & $\begin{array}{l}\text { Utilizam-se indicadores como: Impacto, Transgressão, } \\
\text { Permeabilidade etc. }\end{array}$ \\
\hline $\begin{array}{l}\text { Etapa 4: Lista } \\
\text { de } \\
\text { componentes }\end{array}$ & $\begin{array}{l}\text { M1: Interface Sócio-espacial; } \\
\text { Interface Cultural; Interface } \\
\text { Ecossistêmica. }\end{array}$ & $\begin{array}{l}\text { Nesta etapa são apresentados os principais elementos } \\
\text { que escolhemos para compor cada uma das três } \\
\text { variáveis que têm as Matrizes-Elemento. O objetivo aqui } \\
\text { é delimitar através de elementos ou componentes, }\end{array}$ \\
\hline
\end{tabular}

Colômbia", 2016. No Capítulo 4 e no Apêndice C, a qual está conformada por 8 etapas 4 Matrizes-Elemento, 6 Matrizes de Análise, 3 Quadros de Apoio, 9 Gráficos e um texto de análise dos resultados, a qual envolve elementos da Metodologia de Interfaces de FLACAM, especificamente do que denominamos aqui de "Forma da Interface" (MatrizElemento 4). Está metodologia, de elaboração do autor, utiliza ademais os conceitos de fixos e fluxos trabalhados por Santos (2006), e responde à necessidade de abordar um campo interdisciplinar que ainda carece de propostas metodológicas que permitam valorizar inovações sociais como grandes processos interativos e de carácter territorial. 
Da desconstrução da inovação ao papel ativo da inovação social em ambientes de economia solidária na configuração de territorialidades: proposta metodológica aplicada no estudo de caso Risaralda-Colômbia

\begin{tabular}{|c|c|c|}
\hline \multirow[t]{3}{*}{ das variáveis. } & $\begin{array}{l}\text { M2: Ações; Atributos; Tecido } \\
\text { Circunstancial. }\end{array}$ & \multirow[t]{3}{*}{$\begin{array}{c}\text { matrizes meramente relacionais e assim delimitar nossos } \\
\text { subsistemas de referência, facilitando a construção } \\
\text { mental de quem analisa. }\end{array}$} \\
\hline & $\begin{array}{l}\text { M3. Energia Intersubjetiva: } \\
\text { Necessidades; Desejos; } \\
\text { Projeções. }\end{array}$ & \\
\hline & $\begin{array}{l}\text { M4. Forma: Interface Físico- } \\
\text { Construída; Interface Físico- } \\
\text { Natural; Interface Social. }\end{array}$ & \\
\hline $\begin{array}{l}\text { Etapa 5: } \\
\text { Caminho } \\
\text { metodológico. }\end{array}$ & $\begin{array}{l}\text { Matriz de Análise Conteúdo- } \\
\text { Forma-Movimento. }\end{array}$ & $\begin{array}{c}\text { O Conteúdo da Interface (M2) está diretamente } \\
\text { relacionado com a organização interna das três variáveis } \\
\text { determinadas na Etapa } 1 .\end{array}$ \\
\hline $\begin{array}{l}\text { Etapa 6: } \\
\text { Matrizes de } \\
\text { Análise. }\end{array}$ & $\begin{array}{l}\text { Elaboração de matrizes de } \\
\text { Análise COFOM e COENIFOM. }\end{array}$ & $\begin{array}{l}\text { Elaboração gráfica das matrizes COFOM e COENIFOM } \\
\text { (Conteúdo-Energia Intersubjetiva-Forma-Movimento). }\end{array}$ \\
\hline $\begin{array}{l}\text { Etapa 8: } \\
\text { Análise dos } \\
\text { resultados. }\end{array}$ & Descrição das inovações. & $\begin{array}{l}\text { Texto de análise dos principais resultados da } \\
\text { metodologia. }\end{array}$ \\
\hline
\end{tabular}

A construção de território se dá na apropriação, uso e representação do espaço, processo no qual, como salienta Raffestin (1993), a alteridade (em reconhecimento do "outro" através do autorreconhecimento) e a externalidade configuram a territorialização, "[...] il più formidabile strumento autoconstruttivo" (TURCO, 2010, p. 49). "O processo de territorialização implementa três formas de controle sobre a superfície terrestre: plano simbólico, material e organizativo" (TURCO, 2010, p. 51, tradução nossa). Neste sentido, pensamos que estes três elementos abrangem os principais resultados obtidos, tendo como referência o projeto de territorialização como uma conquista cultural e um dispositivo social que parte do ambiente e vai ascendendo numa construção mental (i)materializada, do que aqui chamamos de território: denominação, num plano simbólico; reificação, num plano material (transformação de algo abstrato em algo concreto, a materialização no controle do material) e estruturação, num plano organizativo (controle organizativo ou as "regras do jogo" social de convivência) que construímos com base em Turco (2010) e Dematteis e Governa (2005) (Figura 3).

Como explica Turco (2010), nestas três formas de controle, o controle simbólico é uma significação, em termos gerais, de mundo; como se vê, percebe, sente e representa, porém, o autor sublinha a "palavra" como o ato territorial por antonomásia, a palavra confere nome, indica posição, predicação, além de atribuir propriedade, entre outras características de grande relevância. Como salienta Turco (2010), a base deste controle é de tipo linguístico, com articulações que afetam o domínio semântico, aquele sintático ou pragmático, podendo-se expressar também de forma figurativa, arquitetônica, em espécie ou verbo-iconicamente.

No que se refere à reificação (também uma coisificação), ou seja, o controle material, Turco (2010) frisa que há uma fusão entre memória histórico-cultural e biológica, incidindo a denominação sobre a materialidade, principalmente pela vontade de transformar a natureza. 
Da desconstrução da inovação ao papel ativo da inovação social em ambientes de economia solidária na configuração de territorialidades: proposta metodológica aplicada no estudo de caso Risaralda-Colômbia

Figura 3 - Níveis de territorialização em relação à aplicação da metodológica: Interfaces Territoriais para Estudos de Práticas de Inovação Social em ambientes Solidários

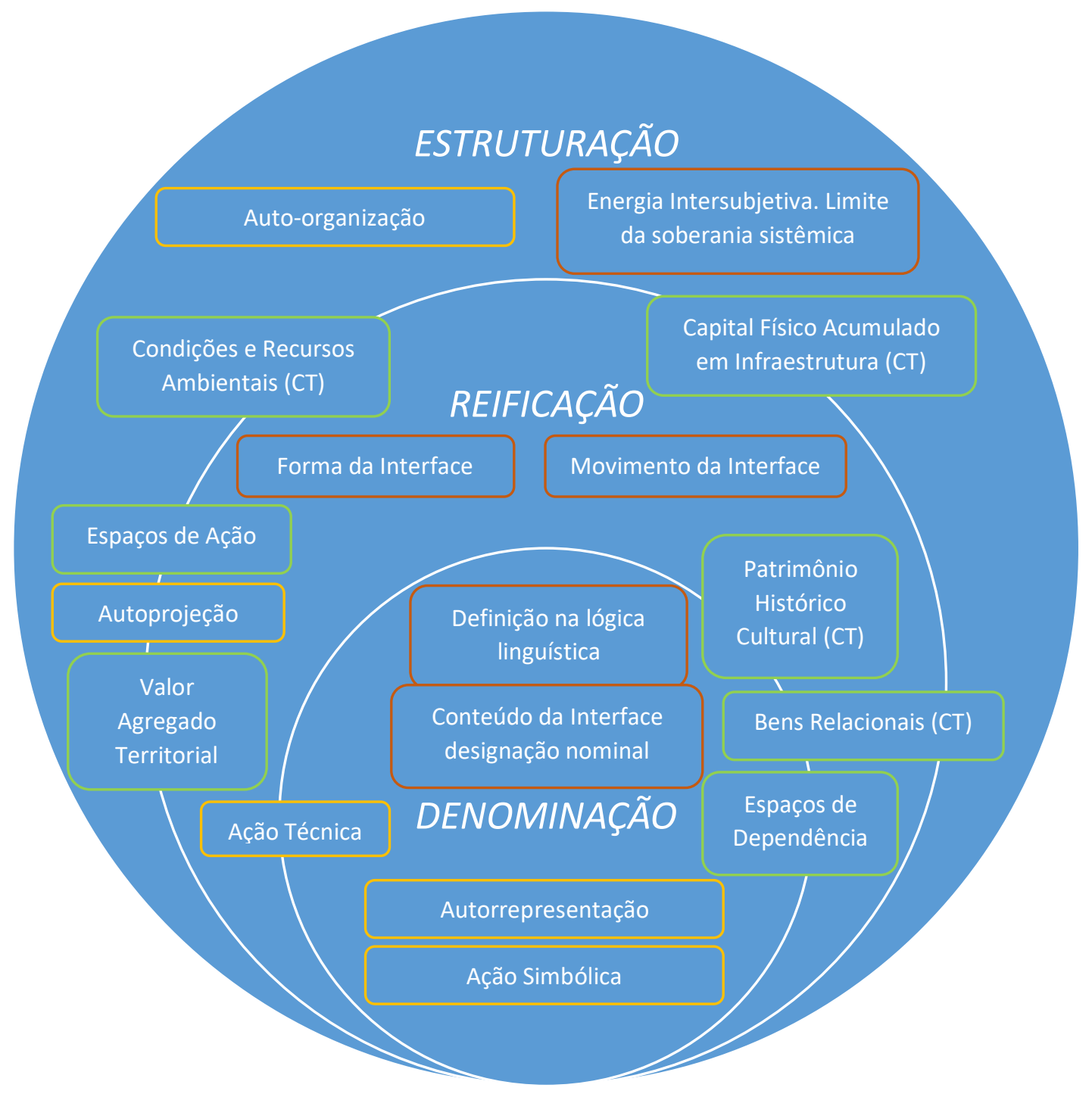

Técnica metodológica. Interfaces territoriais para estudos de práticas de inovação social em ambientes solidários

Etapa 1 SLoT: interdependências do capital territorial na escala relacional: produção, transformação distribuição e valor agregado territorial

Etapa 2 SLoT: auto-organização, autorrepresentação e autoprojeção da ação coletiva na construção de territorialidades vinculadas ao agir técnico e simbólico do trabalho como interfase metabólica culturo-ecossistêmica 
Da desconstrução da inovação ao papel ativo da inovação social em ambientes de economia solidária na configuração de territorialidades: proposta metodológica aplicada no estudo de caso Risaralda-Colômbia

É assim que o evidente poder do homem de exercer controle transforma uma aparente fraqueza, em relação com os outros organismos, na mediação técnico-simbólica, histórica e processual, num mecanismo de adaptação e transformação que vai além da dependência orgânica da qual está sujeito qualquer outro ser vivo, mas que o homem soube territorializar num plano simbólico e material organizado. Já no plano da estruturação há regras políticas, econômicas (como as estruturas dadas na troca e consumo) e culturais que influenciam simultaneamente a vida das pessoas e seu desenvolvimento.

Essas estruturas como esclarece Turco (2010), são ambientes de exercício onde uma regra de competência ou poder se exerce, podemos agregar ao debate, que as estruturas nos Circuitos Econômicos Solidários fazem parte da construção, uso e mediação do território. Como se mostra na Figura 3, representando os três momentos e sintetizando os principais elementos das três formas de controle. Os elementos foram colocados dentro de cada círculo correspondente, porém, um elemento pode ficar em uma ou mais interfaces, isto forma um tecido de três dimensões não precisamente hierárquico, nem exclusivo, inclusive com certa simultaneidade nos acontecimentos.

Os acontecimentos se articulam e produzem numa atividade de construção, uso e mediação do mesmo território, na realidade geográfica, um processo autorreferencial territorializante gerido por uma coletividade, influenciando a própria reprodução da sociedade. Um exemplo disso são as estruturas territoriais, sistemas históricos acumulados, mais ou menos estáveis, com algum grau de autoaprendizagem que obriga a pensar-se como sociedades resilientes.

\section{CONSIDERAÇÕES FINAIS}

Como foi apresentado, foram definidas as três inovações sociais numa lógica discursiva, para gerar uma compreensão da inovação como processo. Os resultados foram verbos como ações principais, adjetivos como atributos e advérbios como tecido circunstancial. A organização Agrosolidaria Seccional Apía demonstrou ter uma visão de integração com uma grande atividade: fortalecer as organizações, só que seu ritmo muito acelerado e os problemas de estrutura administrativa não permitiram atingir o objetivo que esta tinha proposto. $O$ resultado desse trabalho é um imaginário coletivo territorial de ganho de poder, principalmente a partir de uma consolidação do sistema agropecuário econômico-produtivo, apresentando-se a economia solidária como um grande guarda-chuva em que o trabalhador, pela sua própria qualidade, como sujeito, consegue fazer parte de um sistema justo e equitativo.

Por outro lado, a situação de ASCRUD-COOPROCOMD é um pouco diferente, já que seu principal objetivo é gerir um modelo de comercialização através de um consumo próprio organizado e eficaz, o resultado é um processo preocupado mais pela representatividade, na ação simbólica: a palavra mais destacada em algumas entrevistas foi a integração ou a unidade, nada muito diferente com os outros estudos de caso, mesmo assim, a articulação interinstitucional desta organização (como circuito) permite uma autorreferência de credibilidade, forte administrativa e financeiramente.

Pelo contrário, o propósito de Agrosolidaria La Celia de transformar o perfil produtivo do município, parte de uma estrutura bastante frágil e um desafio maior, pois não tem um acúmulo de organizações sólidas e, muito menos, um apoio técnico, administrativo, organizacional, de vigilância e controle real, dito com outras palavras, a Ação Técnica, a qual se apresenta na interface de denominação e reificação (Figura 3) não é completamente operante. Os denominados "Espaços de dependência" (presentes na etapa metodológica da operacionalização e projeção do modelo de análise SLoT, espaços de dependência e espaços de ação, consultar Alzate (2016) e Santangelo (2005)) são evidentes, no entanto, com a falta de segurança e, sobretudo, de soberania alimentar, eles não conseguem suportar os ganhos nos Espaços de Ação, elemento que localizamos dentro da interface material e organizativa.

Resumindo, a inovação social permite olhar para as práticas socioespaciais como um conjunto coordenado de ações que, em seu mesmo movimento criativo de transformação e criação, redefinem a formação e emergência sistêmica dos territórios (como construções sociais 
Da desconstrução da inovação ao papel ativo da inovação social em ambientes de economia solidária na configuração de territorialidades: proposta metodológica aplicada no estudo de

(i)materiais). Deste modo, voltar os olhares em direção à processualidade e multidimensionalidade das sociedades, que por natureza se dotam e redefinem de, e, na espacialidade, é sublinhar o papel das territorialidades na auto-organização, autorrepresentação e autoprojeção da ação coletiva, presente nos processos de governança, identidade e focado nos processos de sustentabilidade. A inovação social só se apresenta aqui, em virtude do exposto, como uma qualificação desse tipo de ações que é legitimada socialmente no íntimo contubérnio entre a realidade e os desejos, ou seja, na sua projeção.

\section{AGRADECIMENTOS}

À Fundação de Amparo à Pesquisa do Estado de São Paulo (FAPESP) e CAPES pelo apoio à pesquisa (processos $n^{\circ}$ 2014/06150-7 e n²015/24127-5) que permitiu uma dedicação exclusiva.

\section{REFERÊNCIAS}

ALZATE, César, A. Circuito Econômico Solidário: Transformações Territoriais Através de Práticas de Inovação Social na Sub-região II do Departamento de Risaralda-Colômbia.

Presidente Prudente: UNESP, 2016, 189 f. Dissertação (Mestrado em Geografia) - Programa de Pós-Graduação em Geografia, Faculdade de Ciência e Tecnologia, Universidade Estadual Paulista "Júlio de Mesquita Filho", Presidente Prudente, 2016.

. Gestión de la innovación en el sector de cafés especiales. Caso de estudio Asociación de Cultivadores de Apía, Risaralda-Asoapia. Sociedad y Economía, Cali, v. 25, p. 135-156, 2013.

ANSHELL, Chris; GASH, Alison. Collaborative Governance in Theory and Practice. Journal of Public Administration Research and Theory, Berkeley, v. 18, p. 543-571, 2008. https://doi.org/10.1093/jopart/mum032

ARENDT, Hannah. Da violência. Brasília: Editora Universidade de Brasília, 1985.

AZEVEDO, Tânia Maris de. Em busca do sentido do discurso: a semântica argumentativa como uma possibilidade para a descrição do sentido do discurso. Caxias do Sul: EDUCS, 2006.

BRITO, Cristovão. Revisitando o conceito de território. Revista do desenvolvimento econômico. Salvador. Ano VI. n. 6, 2002.

CARDENAS, Ruben. Las organizaciones solidarias en Colombia una experiencia alternativa en la modernización del Estado. (Sem local): Observatorio de la Economía Latinoamericana, 2010.

CHECKLAND, Peter; SCHOLES, Jim; CHECKLAND, Peter. Soft systems methodology in action. Chichester: Wiley, 1990.

DELLEUZE, Gilles; GUATTARI, Felix. Anti-édipo, capitalismo e esquizofrenia. Rio de Janeiro: 1976.

DEMATTEIS, Giuseppe; GOVERNA, Francesca (Org.). Territorialità, sviluppo locale, sostenibilità: il modello SLoT. Milão: FancoAngeli, 2005.

GAGLIOTTO, Ana; MEZZOMO, Francieli; BRAGA, Luis. O território e a territorialidade: contribuições de Claude Raffestin. In: SAQUET, Marcos; SOUZA, Edson. (Orgs.). Leituras do conceito de território e de processos espaciais. São Paulo: Editora Expressão Popular, 2009, p. 33-46.

GIBBONS, M. La nueva producción de conocimiento. Barcelona: Pomares Corredor, 1997.

MATTE, Nadja; MOSQUERA, Eli. Deleuze e Guattari e a desterritorialização. In: SAQUET, Marcos; SOUZA, Edson. (Orgs.). Leituras do conceito de território e de processos espaciais. São Paulo: Editora Expressão Popular, 2009, p. 23-32. 
Da desconstrução da inovação ao papel ativo da inovação social em ambientes de economia solidária na configuração de territorialidades: proposta metodológica aplicada no estudo de caso Risaralda-Colômbia

PICINATTO, Antonio; SPIER, Gilberto, VIERA, Ivanildo, DUTRA, Ricardo. Território na Abordagem geográfica de Bertha Becker. In: SAQUET, Marcos; SOUZA, Edson. (Orgs.). Leituras do conceito de território e de processos espaciais. São Paulo: Editora Expressão Popular, 2009, p. 67-77.

RAFFESTIN. Por uma geografia do poder. Tradução de Maria Cecília Fança. São Paulo: Ática S.A, 1993.

ROTHWELL, R. External networking and innovation in small and medium-sized manufacturing firms in Europe. Technovation. v. 11, n. 2, 1991. https://doi.org/10.1016/0166-4972(91)90040-B

SACANELL, Enrrique. Caracterización e impulso del proceso de innovación en las organizaciones. In: MORALES, Carlos. Seminario sobre Innovación Social en el ámbito de los servicios sociales. País Vasco: Edefundazioa, p. 82-87, 2009.

SANTANGELO, Marco. Transcalarità e multiscalarità dello sviluppo locale. In: DEMATTEIS, Giuseppe; GOVERNA, Francesca (Org.). Territorialità, sviluppo locale, sostenibilità: il modello SloT. Milão: FancoAngeli, 2005, p. 68-88.

SANTOS, Milton. A natureza do espaço. Técnica e tempo. Razão e emoção. 4. ed. São Paulo: Editora da Universidade de São Paulo, 2006.

SAQUET, Marcos. Por uma geografia das territorialidades e das temporalidades: uma concepção multidimensional voltada para a cooperação e para o desenvolvimento territorial. São Paulo: Outras Expressões, 2011.

. Por uma abordagem territorial. In: SAQUET, M; SPOSITO, A. (Org.). Territórios e territorialidades: teorias, processos e conflitos. São Paulo: Editora Expressão Popular, p. 73942009.

SOUZA, Marcelo Lopez de. Os conceitos fundamentais da pesquisa sócio-espacial. Rio de Janeiro: Betrand Brasil, 2013.

SOUZA, Marcelo Jose Lopes de. O território: sobre espaço e poder, autonomia e desenvolvimento. In: DE CASTRO, Iná; DA COSTA, César; CORRÊA, Roberto. (Org.).

Geografia: conceitos e temas. Rio de janeiro: Editora Bertrand, 1995, vol. 353, p. 77-116.

TURCO, Angelo. Configurazioni della territorialità. Milão: FrancoAngeli, 2010.

Recebido em: 02/05/2018

Aceito para publicação em: 13/11/2018 